\title{
Do Macro-Economic and Technical Indicators Matter?- a Principal Component Analysis Approach for Equity Risk Premium Prediction
}

\author{
Naveed ul Hassan \\ Dr. Bilal Aziz \\ Maryam Mushtaq \\ Dr. Sadia Farooq
}

\begin{abstract}
Equity risk premium contains the property of reflecting the fundamental judgments of individuals regarding risk that might exists in the economic market and the price associated with that risk. For ERP forecasting, attention is also devoted to technical indicators apart from the macro-economic variables. A set of 14 technical and 14 macro-economic variables is selected for this purpose and based on a standard predictive regression framework; all forecasts are generated by regressing ERP on a constant and a lag of macro-economic or technical indicator. It is found that as compared to macro-economic variables technical indicators provide better indications about ERP estimates. By using National Bureau of Economic Research (NBER) data of business cycle expansion and recessions, relative strength of ERP predictability is also investigated and it is found more than twice for recessions as compare to expansions.
\end{abstract}

Keywords: Equity Risk Premium; Macro-economic Indicators; Technical Indicators; Forecasting. Field of Study: Finance JEL Classification: G00, G12, G17

\section{Introduction}

In the field of financial economics, equity risks are considered as central components of every risk and return model. Considering the above statement being true; the question which arises is that why equity risk premium (ERP) matters? The major reason of this important concept is that the equity risk premium contains the property of reflecting the fundamental judgments of individuals regarding risk that might exists in the economic market and the price associated with that risk. The expected return of every risk is affected during the process and so does value of a particular investment. As a result, it makes difference in allocating wealth across different classes of assets and the selection of such particular assets in each class of asset wherein we intended to invest. It has been theoretically proven that a positive correlation exists between risk and return at the market equilibrium where the expected return of high risk investments is higher which is equal to the total of risk free (Rf) rate and extra return that balance risk.

\section{What is the equity risk premium?}

ERP is a broad term and it has been defined by number of authors in different ways. Annin and Falaschetti (1998) defined equity risk premium as "the reward that investors require to accept the uncertain outcomes associated with owning equity securities. It is an extra return on average that equity holders expect to achieve over risk-free assets." Pratt y Grabowski (2008) described equity risk premium to be an additional compensation demanded by the investors for investing their resources in a diversified portfolio. If the relevant data is available, Equity risk premium can easily be calculated over any period of time. Talking about the U.S stock market we can find 100 years data to measure the equity risk premium.

\section{Equity Risk Premium Puzzle}

The equity risk premium puzzle was started and sketched by (Mehra \& Prescott, 1985). A number of researchers have utilized their methodology to measure equity risk premium i.e "Historical returns, an appropriate proxy for expected returns." Constantinidies, Donaldson, and Mehra (1998) depicted that 6.9 percent deviations in average real annual returns on U.S 
stock market and relatively riskless assets that is considered as equity risk premium and high rate of this premium is labeled as equity premium puzzle.

Recently, different researchers have tried to test the rational expectation models for long term asset prices. These models depicted deviations among the rationally expected returns across assets that have been calculated over a time interval and the difference is because of constant. Typically, the minor returns of one of the asset in the group is already known, thus intuitively, expected return on remaining assets presented by the model is equal to the calculated return by adding the constant in it. The variance among two expected returns is named as risk premium and the expectation model depicted that the risk premia are constant over a time interval1.

\section{Empirical Solutions to Puzzle}

The empirical approach has raised the issue regarding method of equity premium estimation. The historical risk premium that are based on the assumption that believes and attitudes of the investors have changed over time has been criticized time and again. According to assumption believes and attitudes of investors at the start of the 20th century was inclined towards more risky investment than these are currently. Elton et al. (2009) and Damodaran (2011) presented another argument that investors may have sensibly forecast stock market crashes which proves wrong but the lack of signals of these crashes in previous data does not indicate that these could not happened. The volatility that can be observed in the equity market cannot properly represent the strength of the volatility in case of any crash that might significantly decrease consumption and wealth.

Fama and French (2002) advocated that the use of fundamental methods for equity premium estimations is more precise in comparison to historical averages method. Donaldson, Kamstra, and Kramer (2010) took another step forward and created a complex system of consistent conditional models. They used financial statistics like interest rates, price-dividend ratios, Sharpe ratios, growth rate of dividend, volatilities and excess return. With the help of this approach they found the equity risk premium in USA to be between $3 \%-4 \%$, and standard deviation calculated by approach has been the lowest as compare to any other approach. It is worth noting that the concluded this equity risk premium to be conditionally varying. Most of the empirical solutions provided so far have the tendency to get halfway between the equity premium estimated by (Mehra \& Prescott, 1985) and the equity premium values provided by asset pricing models. Therefore, it can be said that these solutions are not sufficient to fully solve the Equity risk premium puzzle.

\section{Theoretical Solutions to the Puzzle}

Elton et al. (2011) pointed out that in order to find possible theoretical solutions for the equity premium puzzle there is a need of developing more sophisticated models of investor utility functions keeping in view how investors perceive risk. Campbell and Cochrane (1999) came up with a different idea which merely changed the perspective on equity risk premium. They formed their model on the basis that investors are not actually afraid of higher risks attached with the stocks, in fact, they are afraid about poor performance of stocks in times of recessions. As per them during such time the consumption of investors also drops significantly. This model however, matches the historically observed equity premium values; nevertheless it fails to be considered as a solution to equity premium puzzle.

Guvenen (2009) came up with an asset pricing model. The estimates of this model are quite similar to the ones observed in historical data. He actually implemented two key properties a) restricted participation in equity market and b) restricted heterogeneity in the in the elasticity of inter-temporal substitution in consumption. His model produced an equity premium of $5.45 \%$ with a volatility of $21.9 \%$. He suggested that both of these values can be compared to historical data and are huge step forward towards solving the equity premium puzzle. Apart from that he also mentioned that the model has some shortcomings like it has been abstracted from long-run growth and it would eventually complicate the already complex model. Elton et al. (2011) suggested that utility analysis should be utilized before understanding the divergence between data and theory as there is a lack of understanding regarding real level of aggregate investor risk aversion.

\section{Equity Risk Premium - Estimation}

1 Expected equity risk premium in Short horizon, intermediate or mid horizon and long horizon is stock market return over 1 month Tbills, over 5 years government bonds and over 20 years government bond respectively, subject to the definitions of lbbotson yearbook. 
In spite of the great importance of equity risk premium in finance it is quite surprising that how haphazardly its estimation has been remained in practice. ERP estimation is one of the most integral components while calculating business firms' cost of capital. It is essentially used in financial decision making. Investors require this estimation for the valuation of stocks, to predict expected returns from the feasibility of investment project, to manage firms from the viewpoint of value creation, and hence to find out the optimal capital structure of firms.

A huge amount of literature has been written on the estimation of equity risk premium. Damodaran (2011) described that there are three broad approaches for estimating equity risk premium. First and the most popular approach is calculating equity premium using historical data. Second is the method of estimating implied equity premium (sometimes called supply side approach e.g. (Goetzmann \& Ibbotson, 2006). And the third approach is to conduct survey and obtain "survey" equity premium. Another method or fourth possibility of obtaining equity risk premium is "Demand approach", an investor utility model (Goetzmann \& Ibbotson, 2006). However, due to the additional complexity connected with this approach it is not convenient for practical use to extract equity risk premium. This thesis will focus on the historical equity premium approach since it is considered to be the most popular approach.

\subsubsection{Historical Equity Premium}

This approach uses historical data to estimate equity premium and considered to be the most popular approach. In this approach, difference between the actual returns earned on stocks over a long period and returns earned on a default-free asset, usually government security is taken. It is expected that the historical equity premium estimations can significantly differ between each other. In order to compare different estimations, one has to take into account some of important factors. Fama and French (1996) suggested seven factors: Geometric or arithmetic averaging, Short or long investment horizon1, Short run or long run expectations2, Unconditional or conditional on some related variable3, USA or International market data, Data sources and periods, Real or nominal returns4.

It is considered that the estimation results of equity risk premium through geometric averaging are usually low as compare to arithmetic averaging. Especially in case, if there are negative returns in the data set of stock market returns. However, the literature suggests that many estimations services and academics support the use of arithmetic average (Damodaran, 2011). Campbell and Cochrane (1999) and Damodaran (2011) are of the belief that there is a long term negative autocorrelation in equity returns which in turn will overstate the results of equity risk premium. As economic and financial environment is changing so it can be assumed that the investor preferences also change over time along with the equity risk premium. This belief is also shared by (Arnott \& Bernstein, 2002; Brown \& Otsuki, 1993; Campbell \& Cochrane, 1999; Chan, Karolyi, \& Stulz, 1992; Donaldson et al., 2010; Gameiro, 2008; Graham \& Harvey, 2005; Lettau, Ludvigson, \& Wachter, 2008; O'Hanlon \& Steele, 2000).

\section{Using estimates or market projections}

In this method it is assumed that equity risk premium can be predicted from surveys or some other projection models. In majority of cases, equity risk premium models use historical data and assume that some past time span explain the best predication of the future. There are certain limitations of this approach even in the markets of long historical data like United States and is entirely useless in the emerging markets with limited or noisy data. There are others ways that can be suggested in which equity risk premiums can be estimated for these markets by using a base equity premium and country risk premium.

\section{Using implied premium}

\footnotetext{
1 Even if the objective is to approximate current of future (i.e. for the next ten years) equity risk premium

2 Short term forecasts are generally conditionally estimated

3 This is not of concern if risk free asset returns and equity returns are computed in same term. Usually, equity premium calculated via real returns are biased downward with 30 basis points (McCulloch \& Leonova, 2005).
}

4 Technical indicators are often computed using monthly, weekly, or daily data. Technical indicators are estimated by use of monthly data. So, to put the forecasts based on macroeconomic variables and technical indicators forecasts can be applied on more equal footing. 
There is another approach for calculating ERP that uses the premiums implicit in current prices, usually in stock market. Goetzmann and Ibbotson (2006) suggested a possible solution to obtain up-to date and current estimation of equity risk premium, referred to as the supply side approach. As per this model all of the asset prices actually represent the expected future cash flow from the asset. For example, the Gordon growth model states that

$$
E_{0}=\frac{D i v_{1}}{k_{e}-g_{t}}
$$

Where;

$\mathrm{E} 0=$ Current value of equity

Div1 $=$ Expected dividend in the next period

$\mathrm{Ke}=$ required rate of return for equity investors

$\mathrm{g}=$ growth rate in dividends forever

Assuming the stable growth scenario the expected growth rate should be equal to risk-free rate, hence the dividend yield on equities would become a measure of the equity risk premium.

$$
\frac{\text { Div }_{1}}{E_{0}}=\text { Dividend Yield }=\text { Equity Risk Premium }
$$

Rozeff (1984) named this rule as "The Golden Rule of Accumulation". He presented a model on the assumption where economy maximizes the consumption per capita, in such case the rate of growth of output equals the physical marginal productivity of capital, which inturn equals the rate of interest. Hence the real dividend growth approximately equals the real rate of interst. Thus, he concluded that this method of using dividend yield as an estimate of equity risk premium is unbiased and has a significatn edge over the historical risk premium estimates. Fama and French (2002) argue in favor of calculating equity premiums using supply-side approach. He wrote that in order to estimate expected stock returns, the expectations of the investor can be judged well by using fundamental variable i.e. dividends and earnings. These approaches are based on the statement that average stock return is the average dividend yield plus average rate of capital gain.

Assuming that the dividend price ratio is stationary means in the samples that include long time periods, the compound rate of dividend growth become equal the compound rate of capital gain hence leading to dividend growth model.

$$
A\left(R D_{g}\right)=A\left(\frac{D_{t}}{P_{t-1}}\right)+A\left(G D_{t}\right)
$$

Practical implications of this model are same as of the model put forward by (Damodaran, 2002). Equity premium can be estimated by subtracting risk-free rate from the stock returns. But this approach only works as a long-term approach. Campbell and Cochrane (1999) found the correlation between consumption growth and dividend growth (thus growth of the whole economy) to be low as 0.05 in short term and 1 in long term. Dividend yields have some predicting power on stock returns and this power increases on longer time horizon (Kurz, Jin, \& Motolese, 2005).

Damodaran (2002) and Fama and French (2002) suggested that assuming a stable future growth and earnings-price ratio to be constant, the above given approach can be reformed to focus on company earnings instead of dividends. If the equation of sustainable growth is taken and substituted in dividend growth model, the implied equity premium can be written as:

$$
I E R P=\frac{E}{P}-R_{f}
$$

Where;

IERP - implied equity premium; $\mathrm{E}$ - expected earnings in the next period, $\mathrm{P}$ - value of equity; Rf - risk free rate. 
Apart from incorporation of stable growth in these models several stages of growth can also be accounted. However, there is a danger associated with such models i.e. at any time period markets can be mispriced. Current implied equity premiums can be obtained but this does not mean that the premiums are long term equilibrium premiums (Goetzmann \& Ibbotson, 2006).

\section{Determinants of Equity Risk Premium}

Many authors have used macro-economic variables to explain level and variations in the market risk premium as the ERP represents rate of return required by the investors currently. In spite of the fact that technical indicators are being widely used by the practitioners as (A. Lo \& Hasanhodzic, 2010); technical indicators have been given less attention in the literature for evidencing the stock predictability relative to macro-economic variables. Some of the existing studies analyze the profitability of the trading strategies based on a variety of technical indicators, including moving averages (Brock et al., 1992; Zhu \& Zhou, 2009), momentum (Ahn, Conrad, \& Dittmar, 2003; Conrad \& Kaul, 1998) etc. These studies however, do not specifically analyze the predictability of EPR, which has been the focus of literature on ERP based on macroeconomic variables.

\section{The Forecast Ability of the Market Risk Premium}

It is documented that stock returns are predictable to some extent, e.g., (Campbell, 1987; Elliott \& Müller, 2006; Fama \& French, 1988a, 1988b, 1989; Ferson \& Harvey, 1999; French, Schwert, \& Stambaugh, 1987) and the literature generally shows an agreement that expected returns are time varying, e.g., (Campbell, Lo, \& MacKinlay, 1997). By definition, the Equity risk premium is the reward in terms of extra return that investors demand for holding risky assets rather than short term nominal risk-free assets. These risk free assets are proxied by short term T-bill rates, and are not constant over time. The volatility of short term nominal risk free rates calculates time variation in the ex-ante nominal risk free interest rate, not risk, since these securities have no default. Therefore, those variables that have forecast abilities for stock returns also forecast the time varying excess stock returns, which is the market risk premium. This is the reason that many researches on the predictability of the stock returns i.e (Campbell, 1987; Campbell et al., 1997; Elliott \& Müller, 2006; Ferson \& Harvey, 1999) also use the same set of explanatory variables to predict the market risk premium.

"Uncertainty about the change in the spot rate creates more uncertainty in a bill's premium the longer the maturity of the bill. If this source of uncertainty is positively associated with the types of risks that the market compensates, then expected premiums on bills will be an increasing function of maturity, and any changes through time in the degree of uncertainty about changes in spot rates will have a greater effect on a bill's expected premium the longer the maturity of the bill."(Fama, 1976, p. 436)

\section{Macro-economic Indicators:}

A number of authors have tried to use macro-economic variables to explain level and variations in the market risk premium as the ERP represents rate of return required by the investors currently. Economic indicators are taken on the basis of economic reasoning. Economic indicators ability to predict equity risk premium directly impacts the economic value of investment strategies (Baetje \& Menkhoff, 2015). Different set of economic indicators are used by different researchers such as dividend price ratio, inflation rate, interest rates, market volatility etc. Macro-economic variables have this power to predict equity risk premium sue to their ability to capture fluctuations in macro-economic conditions (Cochrane, 2011).

In this paper the authors has devoted his attention apart from macro-economic variables to technical indicators as well for the purpose of forecasting the ERP. Further, in this paper performance of both macro-economic variables and technical indicators for predicting ERP is compared. In comparing the technical and macro-economic predictors, all forecasts are generated based on a standard predictive regression framework, where ERP is regressed on a constant and a lag of a macro-economic variable or technical indicator.

To prudently incorporate information from many predictors, predictive regressions are estimated based on a small number of principal components extracted from the entire set of macro-economic variables and/or technical indicators. This study used the data spanning from December 1992 to December 2013 for 14 well known macro-economic variables suggested 
by (Welch \& Goyal, 2008) and 14 technical indicators from the existing literature based on moving averages, momentum and volume.

\section{Technical Indicators of Market:}

Technical analysis is considered as a persistent activity for security market and future market. As the technical analysts rely on price and volume data that provides indication of future price movements and through examining these one can extract the information on the fundamentals driving. On technical analysis, classic work is generally considered to (Edwards, 1957). Neftci (1991) empirically tested some of the common rules used in technical analysis for price change.

Moving average rule is regarded as one of the common component of technical rules. It includes calculation of moving average from raw data and most common form of it shows buy and sell signal. Whenever the price climbs above the moving average it gives a buy signal and whenever the price drops below the moving average its gives sell signal. The basic idea behind this rule is that it is helpful in providing means of determining the direction or trend of a market by analyzing the recent history. There are different rules of moving averages based on the time horizon. 1-200 rule of moving average is considered as the most popular rule, where the short period is of one day and the long period is of 200 days. Some other popular rule are 1-50, 1-150, 5-200 and 2-200 rules (Brock, Lakonishok, \& LeBaron, 1992).

Apart from moving averages of the stock returns, technical trading rules are also closely related to Momentum strategies. These strategies involve buying winner stocks and selling looser stocks. The academic authors think that momentum is an enduring anomaly which led (Fama \& French, 2008, p. 1653) to describe it as "pervasive". The two factors i.e. buying winner stocks and selling looser stocks have resulted in a large amount of research being conducted in investigating whether technical trading rules are profitable. Both kinds of views can be extracted from the literature demonstrating that technical analysis does not add value in the US equity market, but several authors have presented supportive evidence in emerging markets (Bessembinder \& Chan, 1995; Ito, 1999).

Another type of technical trading rule which has been widely used by the technical analysts and professionals is Volume. Volume has a significant part in markets and has long been an area of empirical research, as Gallant, Rossi, and Tauchen (1993) and Karpoff (1987) presented a quality review of earlier studies.

\section{Research Objectives}

The study is carried out to analyze the equity risk premium forecasts by using technical and economic fundamentals i.e. technical variables and macro-economic variables. Further, the study aims to compare the capacity of technical indicators to forecast equity risk premium with that of macro-economic variables. This ability of both indicators (macro-economic and technical) is also assessed over the business cycle.

Following are the main objectives of this study:

To forecast Equity Risk Premium by directly relying on macro-economic variables

To forecast Equity Risk Premium by directly relying on technical indicators

To compare the capacity of both indicators in predicting Equity Risk Premium

To determine the incremental role of both indicators

To predict Equity Risk Premium over the business cycle (peaks and troughs).

\section{Significance of Study}

The premium has principle importance and plays an integral role in finance and is the basis of various applications. This precise technique is used by many financial managers for estimation of cost of capital, investment appraisal and financing decisions. The overall cost of capital of the firm is used when the company is going to undertake some future project plans and mostly for the evaluation of present value of future cash flows. Equity premium is equally important for corporate managers for financial decision making as it's a main determinant of cost of equity and it assists in selecting debt and equity proportion suitable for the firm. 
It is also significant for the investment analysts, for using in portfolio asset allocation and evaluation of investment performance. As normally equities are among the most risky type of assets and so the Equity Premium. Performance evaluation of individual equities, portfolio or funds is also dealt with equity premium by investment analysts. Fund managers also required to consider performance evaluation as relative to the benchmark and hence evaluated to what extent they are successful to manage and to make value for their investor relative to what was expected. It is also essential for the Actuaries to know exact measure of Equity Premium for the purpose of long-term financial planning mainly of personal pension funds.

\subsection{Methodology}

The literature of Equity Risk Premium is hard to absorb. As in earlier studies; different methodology, variables, techniques and time period has been used. Findings of those studies which were written in the past may be changed when latest data is used. It has also been evidenced that the findings of such studies contradict others. Still, most of the readers have think that prediction works even if it is not clear that what really works. However, the established tendency in literature is possibly best summed up by Lettau and Ludvigson (2001).

"It is now widely accepted that excess returns are predictable by variables such as dividend-price ratios, earnings-price ratios, dividend-earnings ratios, and an assortment of other financial indicators."

\section{Data Collection Sources and its Structure}

As the study aims to check the capacity of economic and technical indicators to predict equity risk premium, so the study use two sets of independent variables i.e. 14 macro-economic variables and 14 technical indicators respectively against one dependent variable i.e. Equity risk premium. Detail description of all these variables is given in this section.

\section{Dependent Variable - Equity Risk Premium}

The main concern of this research is predicting the equity risk premium i.e. dependent variable. Different researchers have given different methodologies to calculate Equity Risk Premium. But, the author has used the widely accepted methodology which is total stock market's rate of return less the existing short term interest rate.

\section{Stock Returns}

In this research Standard \& Poor 500 index return has been used. The month end values have been retrieved from CRSP (Center of Research in Security Press) from 1926 to 2013. Stock returns used in this study are the continuously compounded returns on the S\&P 500 index, including dividends.

\section{Risk-free Rate}

Literature on risk free short-term debt prior to 1920s was not available; hence the risk-free rate has been used from 1920s onward till 2013. The first set of independent variables in this research is mainly the stock characteristics. So, the ERP is taken as the difference of continuously compounded return on S\&P 500 together with dividends and log return on a risk free asset.

\section{Independent Variables}

Two types of Independent variables have been taken in this study. First type of independent variables include 14 Macro economic variables which are taken from the study of (Welch \& Goyal, 2008) and represent the set of Xi,t variables; applied for the prediction of equity risk premium. Second type of independent variables includes 14 technical indicators consisting of Moving averages, Momentum and Volume.

\section{Macro-economic Variables}

Following are the 14 macro-economic variables, representing the literature of (Welch \& Goyal, 2008) and (Neely, Rapach, Tu, \& Zhou, 2014) used to predict equity risk premium:

Dividends are 12 months moving sums of dividends paid on the S\&P 500 index. The data regarding this has been retrieved from Shiller's website from 1871 to 1987. 
Dividend-Price ratio: Dividends from 1988 to 2013 are taken from S\&P Corporation. The dividend price ratio is taken as the difference between dividends (log) and prices (log).

Dividend yield: Dividend yield is the difference between the log of dividends and the log of lagged prices (Ball, 1978; Campbell, 1987; Fama \& French, 1988a; Hodrick, 1992; Rozeff, 1984; Shiller, Fischer, \& Friedman, 1984).

Earning is taken as the moving sums of 12 months earning on S\&P 500 index. This data is retrieved from the Shiller's website from 1871 to 1987 whereas earnings from 1988 to 2013 are taken from (Welch \& Goyal, 2008).

Earning price ratio: It is taken as the difference of log of earnings and log of prices. In this research, distinction has also been considered in which the researcher explored multiyear moving averages of numerator or denominator that is moving ten years average of earning divided by price.

Dividend payout ratio: Dividend payout ratio is taken as difference between dividends (log) and earning (log) as used in (Campbell \& Shiller, 1988).

Equity risk premium volatility: To avoid the problems due to outliers in October 1987, Neely et al. (2014) used the volatility measure recommended by (Mele, 2007) that is based on 12-month moving standard deviation estimator. So, the proxy used to measure equity risk premium volatility is defined as:

$$
\begin{gathered}
\hat{\sigma}=\frac{1}{2} \sum_{i=1}^{12}\left|r_{t+1-i}\right| \\
\widehat{r v o l}_{t} \equiv \sqrt{\frac{\pi}{2} \sqrt{12}} \widehat{\sigma}_{t}
\end{gathered}
$$

Book-to-market ratio: It is taken as ratio of book value-to-market value for the Dow Jones Industrial Average.

Net equity expansion: It is a ratio of 12-month moving sum of net equity issued by New York Stock Exchange (NYSE) listed stocks to the total (end of year) market capitalization of NYSE stocks.

Treasury bills: Treasury bill rates are the yields on short term U.S Securities from 1920-1933, treasury notes and certificates of three to six months and treasury series in the NBER for three months Macro History Database. Treasury bill rates from 1934 to 2005 are the three month treasury bill; secondary market rate from the economic research data base at the Federal Reserve Bank at St. Louis (Campbell, 1987).

Long term yield: The long term government bond yield data from 1919 to 1925 is the U.S Yield on long term United States Bonds series in the NBER's macro history database. Yield from 1926 to 2013 are from Ibbosto's Stock, Bonds, Bills, and Inflation yearbook.

Long term rate of return: Long term rate of return data is retrieved from the lbbotson's stock, bonds, bills and inflation yearbook. It is the long term government bond yield. This data starting from 1919 to 2013 has been taken from (Welch \& Goyal, 2008).

The term spread: It is the difference between the long term yield on government bonds and the Treasury bill (Fama \& French, 1989).

Default yield spread: It is the difference between BAA and AAA rated corporate bond yields.

Default return spread: It is taken as the difference of long term corporate bond and long term government bond returns (Keim \& Stambaugh, 1986).

Inflation: Inflation is a macro-economic indicator and is the consumer price index for urban consumers from 1919 to 2013 and has been taken from Bureau of Labor Statistics (Campbell \& Vuolteenaho, 2004).

\section{Technical Indicators}

To compare the technical indicators with macro-economic variable, the researcher has used 14 technical indicators which are based on three trend following strategies. 
The complete set of 14 technical indicators is based on three types of famous technical trading strategies. At the completion of each period, all of those indicators give a buy/sell signal according to recent price movements.

\section{Moving Averages}

The moving average of some specific time period is calculated as; adding up the most recent data and then divided by time period. The moving average is calculated every time by omitting old values and adding up the most recent values. Hence, average shifts as the data moves but doesn't have enough variation and is smoother than the p-period moving average where $p=5 n$ and calculate longer trend. Based on moving average, six technical trading strategies are generated i.e. MA(1,9), (1,12), (2,9), $(2,12),(3,9)$ and $(3,12)$ as used in (Brock et al., 1992; Zhu \& Zhou, 2009). These trading strategies compare short (1-3 months) and long (9-12 months) moving averages to forecast the stock price trends.

\section{Momentum}

There are two technical trading strategies retrieved by comparing current prices with past prices of the stock i.e. MOM(9) and MOM(12) momentum rules as used by (Ahn, Conrad, \& Dittmar, 2003; Conrad \& Kaul, 1998). If stock's current price increases than the level of 9 to 12 months before then trading rules recommend buy i.e. a trend following perspective.

\section{Volume}

The third category depends on volume rules. These six technical trading indicators associate volume to price changes in which short term is considered as one to three months and long term is considered as nine to twelve months for detecting strong price trends as suggested by (Granville, 1963). This forms VOL(1,9), $(1,12),(2,9),(2,12),(3,9)$ and $(3,12)$ trading volume strategies.

Volume is important because price movements are confirmed by high trading volume that generates signals regarding stock price trends. Grundy and McNichols (1989) and Blume, Easley, and O'hara (1994) proved that such trading volumes provides valuable information that is beyond the prices.

\section{Empirical Estimations}

OLS is used to estimate the base regression coefficients; however, bootstrapped F-statistics has been calculated to compute the significance of variables by taking into account correlation of the independent variables.

\subsection{Bivariate Predictive Regressions}

The author has used the following predictive regression model for analyzing ERP predictability based on the macroeconomic variables:

$$
R_{t+1}=\alpha_{i}+\beta_{i} x_{i, t}+\varepsilon_{i, t+1}
$$

In the above equation, $r t+1$ shows the return of large stock market index from the period $t$ to $t+1$, in excess of (Rf) risk free rate. Further, xi,t shows the predictor presented at time $t$; and $\varepsilon i, t+1$ is zero-mean disturbance term under Null hypothesis of no predictability $\beta \mathrm{i}=0$. So, we can infer that $\beta \mathrm{i}$ being the Alternate hypothesis will be positive. As per Inoue and Kilian (2005) a one-sided alternate hypothesis increases the power of in-sample tests predictability. As a result, equation (1) reduces to the constant expected ERP model. In the paper $\mathrm{HO}$ : $\beta \mathrm{i}=0$ against $\mathrm{HA}: \beta \mathrm{i}>0$ has been tested using a hetroskedasticity consistent t-statistic related to $\hat{\beta} \mathrm{i}$ that is an OLS estimate of $\beta \mathrm{i}$ shown in equation (1). But it has been evidenced that bias potentially inflates the t-statistics for $\widehat{\beta} \mathrm{i}$ of equation (1) and distorts test size when xi; is highly persistent, as is the case for a number of popular predictors (Stambaugh, 1999). To cater this issue we used wild bootstrap process to compute p-values (Neely et al., 2014). This process is known for accounting the regressors' persistency along with the general forms of heteroskedasticity and correlations between equity risk premium and predictor innovations.

\section{Strategies to Estimate Technical Indicators}

For technical indicators we composed dummy variables using the following strategies. The first strategy is the use of moving averages that helped to generate a buy or sell signals of a stock $(\mathrm{Si}, \mathrm{t}=1$ or $\mathrm{Si}, \mathrm{t}=0$ ) respectively by comparing two moving averages at the end of time $t$. 


$$
S_{i, t}= \begin{cases}1 & \text { if } M A_{s, t} \geq M A_{l, t} \\ 0 & \text { if } M A_{s, t} \geq M A_{l, t}\end{cases}
$$

Where;

$$
M A_{j, t}=1 / j \sum_{i=0}^{j-1} P_{t-1} \quad \text { for } j=s, l ;
$$

Pt in the above equation, represent stock price index level and $s(l)$ denotes length of the short (long) moving averages $M A(s<1)$. This indicated about the changes in the stock price trend because short moving average is very sensitive to recent price movement of stock than long moving averages. In the research MA indicator has been denoted with MA lengths and 1 by MA $(s, 1)$ where $s=1,2,3$ and $l=9,12$. The researcher calculated monthly signals from moving averages.

The second strategy that has been employed is based on momentum and its equation is

$$
S_{i, t}= \begin{cases}1 & \text { if } P_{t} \geq P_{t-m \prime} \\ 0 & \text { if } P_{t} \geq M A_{t-m}\end{cases}
$$

If stock price is higher than its previous period, it indicates positive momentum and generates buy signals. In the research the monthly signals have been calculated. Intuitively a "positive" momentum is when price of current stock is more than the level in $\mathrm{m}$ periods before, this leads to higher expected excess returns, thereby generating a buy signal. Momentum indictor is denoted by $\mathrm{MOM}(\mathrm{m})$ and by this indicator Pt is compared with Pt-m, and monthly signal for $m(9,12)$ is computed.

As per the technical analysts, market trends are identified by volume data in conjunction with the earlier prices. In light of such intuition, the technical strategy of On-balance volume is considered e.g., (Granville, 1963).

$$
O B V_{t}=\sum_{k=0}^{t} V O L_{k} D^{\prime}
$$

In the above given equation VOLk measures the trading volume during period $\mathrm{K}$. As per this strategy $\mathrm{Dk}$ is a binary variable that acquires value of 1 if the value of Pk-Pk-1is greater than or equal to 0 and -1 otherwise.

So, trading signals from $\mathrm{OBVt}$ are formed as:

$$
S_{i, t}= \begin{cases}1 & \text { if } M A_{s . t^{O B V}} \geq M A_{l, t^{O B V}} \\ 0 & \text { if } M A_{s, t^{O B V}} \geq M A_{l, t^{O B V}}\end{cases}
$$

Where;

$$
M A_{j, t} \text { OBV }=1 / j O B V_{t}=\sum_{i=0}^{j=1} O B V_{t-1} \quad \text { for } j=s, l
$$

Let's assume that there is a recent price increase along a high volume. This indicates a strong positive market trend and it will generate a buy signal. We denoted the corresponding signals by VOL(s,l) while computing monthly signals of $s=1,2,3$ and I=9, 12. Sullivan, Timmermann, and White (1999) observed that MA, momentum and volume based indicators represent trend-following technical indicators considered in literature. The lags have also been accounted for constructing the technical indicators and found that observations of all of the indicators are available from 1992:121. The technical indicators generate buy signals $(\mathrm{Si}, \mathrm{t}=1)$ between $66 \%$ to $72 \%$ of the time. We then transformed the technical indicators by substituting xi,t in (1) with Si,t from equation (2), (4), or (6) to forecast equity risk premium. The sole purpose of this activity is to make comparison of technical indicators to ERP forecasts on the basis of macro-economic variables.

1 The data are available from Amit Goyal's webpage at http:// www.hec.unil.ch/agoyal/. 


$$
R_{t+1}=\alpha_{i}+\beta_{i} S_{i, t}+\varepsilon_{i, t+1}
$$

Because $\mathrm{Si}, \mathrm{t}=1(\mathrm{Si}, \mathrm{t}=0)$ represents a bullish (bearish) signal, we again test $\mathrm{HO}: \beta i=0$ against $\mathrm{Ha}: \beta i>0$.

\subsection{Empirical Results and Analysis}

The data for this research has been taken from (Welch \& Goyal, 2008)1. The authors estimated the predictive regressions using this data where the ERP is the difference between the continuously compounded return on the S\&P 500 (including dividend) and the log return on a risk-free bill.

\section{Bivariate Regression Results}

Table 4.2 provides estimation of bi for the bivariate predictive regression explained in equation (1) and (8). Further you can also see the heteroskedasticity-consistent t-statistics and R2 statistics in the same table. The researcher has taken the data from 1951 to 2013 which comprise of 757 observations. Among 14 variables, six of the variables showed significant results which are DY, RVOL, TBL, LTY, LTR, and TMS. Among these six significant predictors the dividend yield, Treasury bill rate, and term spread. According to bivariate regression, $\mathrm{R} 2$ value seems very low which in turn lead to rejection of the model. But as a matter of fact, monthly stock returns inherently contain substantial unpredictable component. Campbell and Thompson (2008) stated that a monthly R2 near $0.5 \%$ can depict economically significant degree of equity risk premium predictability. R2 of Five variables are exceeding the benchmark of $0.5 \%$. The result of technical variables depicted that 13 out of 14 variables showed significant results and R2 of ten variables are more than 50 percent. The coefficient estimates presented that a buy signal estimate that the next month's equity risk premium is higher by 48 to 94 basis points than when there is a sell signal. The results showed that technical indicators are giving better indications about equity risk premium estimates as compared to macro-economic variables.

The scope of this paper is not limited to just ERP predictability as the researcher also investigated the relative strength of equity risk premium predictability by using National Bureau of Economic Research (NBER) data of business cycle expansion and recessions. Researcher computed the following intuitive versions of the conventional R2 statistics for comparing the degree of return predictability across expansion and recessions.

$$
R_{c}^{2}=1-\frac{\sum_{t=1}^{T} I_{t}^{c} \hat{\varepsilon}_{i, t}^{2}}{\sum_{t=1}^{T} I_{t}^{c}\left(r_{t}-\bar{r}\right)^{2}} \quad \text { for } c=E X P, R E C
$$

The dummy variable was created in a way where $I_{t}^{E X P}$ value of unity when month $\mathrm{t}$ is an expansion and $I_{t}^{R E C}$ takes value of zero when month $\mathrm{t}$ is a recession., $\hat{\varepsilon}$ i, tis the fitted residual based on the full-sample estimates of the predictive regression model in (1) or (8), $R$ is the mean value of rt here $t$ is the number of usable observations for the sample. Observe that, unlike the full-sample R2 statistic, the R2EXP and R2REC statistics can be negative.

Table 4.1 depicted the ERP predictability and it has been observed that ERP predictability for the following variables is higher for recession vis-a-vis expansion for a number of the macro-economic variables, including DP, DY, RVOL, TBL, LTR, TMS and DFR whereas predictability of technical indicator is high in recession.

Table 4.1 Bivariate Predictive Regression Results

\begin{tabular}{|l|l|l|l|l|l|l|l|}
\hline & $\begin{array}{l}\text { Slope } \\
\text { coefficient }\end{array}$ & t-statistic & $\begin{array}{l}\text { One-sided } \\
\text { (upper-tail) wild } \\
\text { bootstrapped } \\
\text { p-value }\end{array}$ & R2 & $\begin{array}{l}\text { R2, } \\
\text { expansion }\end{array}$ & R2, recession \\
\hline \multicolumn{7}{|l|}{} & \\
\hline MACRO-ECONOMIC VARIABLES & & & & & \\
\hline Bivariate & & & & & \\
\hline DP & 0.5692 & 1.0397 & 0.8970 & 0.0029 & & \\
\hline DY & 0.6501 & 1.2000 & 0.1160 & 0.0037 & & \\
\hline EP & 0.3812 & 0.6475 & 0.4410 & 0.0015 & & \\
\hline DE & 0.1413 & 0.1953 & 0.4650 & 0.0001 & & \\
\hline
\end{tabular}

1 (Ludvigson \& Ng, 2007, 2009) estimate predictive regressions for excess stock and bond returns, respectively, based on principal components extracted from macroeconomic variables 


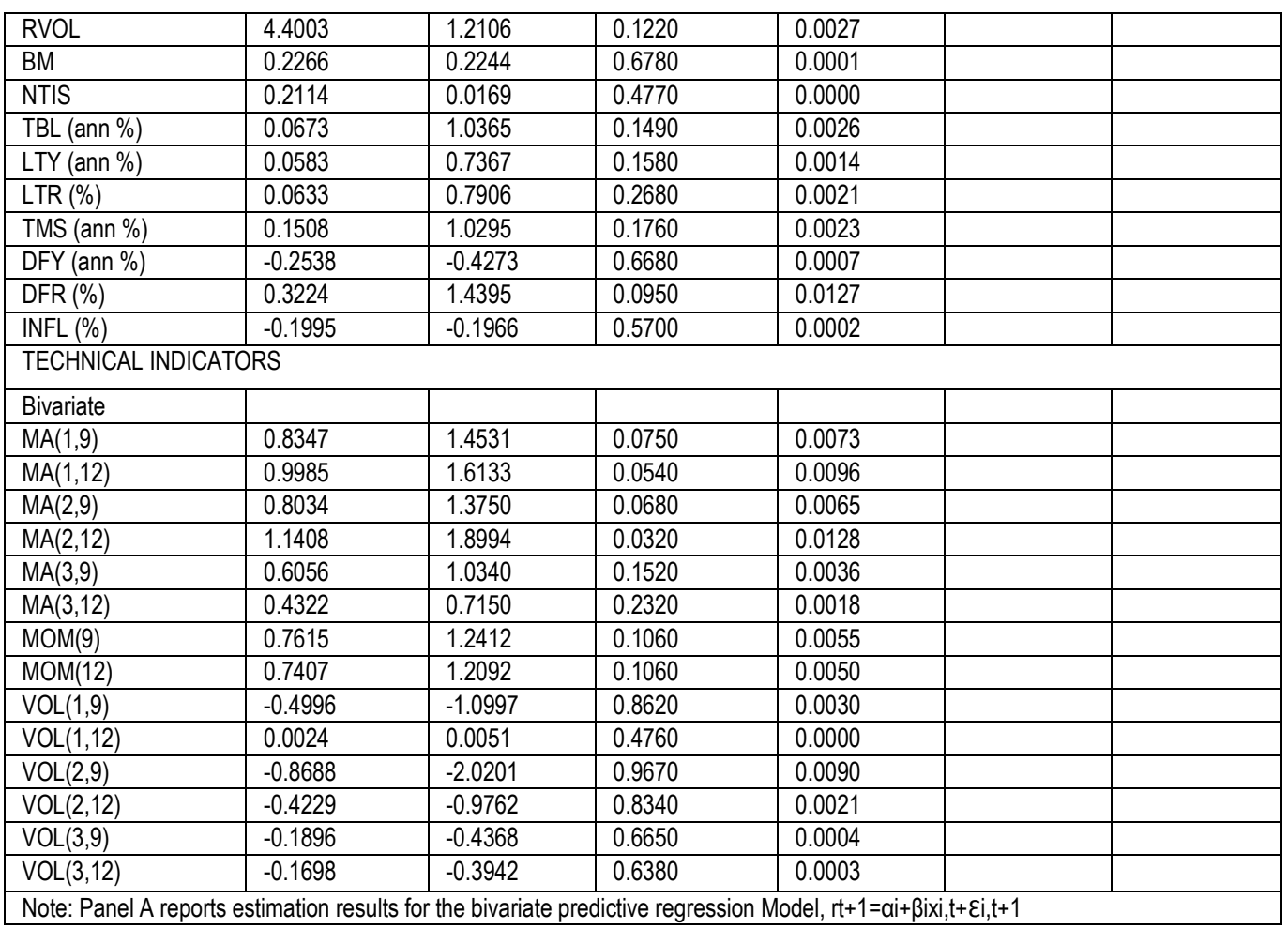

\section{Principal Component Regression Results}

After testing for the bivariate regression analysis of 14 macro and 14 technical indicators we moved to predictive regression based on principal components1. Below given equation represents the Principal component predictive regression (PCECON model) Assuming $x t=(x 1, t, \ldots \ldots . . x N, t)$ denote the $\mathrm{N}$-vector of all the 14 macro-economic variables $(\mathrm{N}=14)$. Similarly assuming $\widehat{F}_{t}^{E C O N}=\widehat{F}_{1}^{E C O N} \ldots \ldots \hat{F}_{k}^{E C O N}$ symbolizes vector containing first $\mathrm{K}$ principal component extracted from $\mathrm{Xt}$ (where $\mathrm{K}<<\mathrm{N}$ ).

$$
r_{t+1}=\alpha+\sum_{k=1}^{K} \beta_{k} \hat{F}_{k, t}^{E C O N}+\varepsilon_{t+1}
$$

One of the major attributes of principal component analysis is that it prudently incorporates the information from a large number of predictors in a predictive regression. However, it has been evidenced that the first few principal components identify the key co-movements among the entire set of predictors. This characteristic filters out noise in individual predictors and guards against the in sample over fitting. Due to this we standardized the individual predictors before the computation of principal components.

The authors estimated the equation (10) via OLS and computed hetroskedasticity-consistent t-statistics shown in the table 4.1. However, the inference has been derived on the basis of wild bootstrapped $p$-values. This has been estimated with

1 The Akaike information criterion also selects $\mathrm{K}=3$. To keep the model reasonably parsimonious, we consider a maximum $\mathrm{K}$ value of three, given the 14 macroeconomic variables. Note that we account for the "estimated regressors" in (10) via the wild bootstrap procedure. 
$\mathrm{K}=3$ and the value has been selected on the basis of adjusted R2.1 The table 4.2 shows that the first two components of the estimate are insignificant however the third principal component is highly significant at $1 \%$ level. Further, the R2 for the PC-ECON model is $1.09 \%$. The table 4.3 also shows the R2 results of expansion and recession i.e. R2 EXP is .76\% and $\mathrm{R} 2 \mathrm{REC}$ is $1.86 \%$ statistics, thus we can say that equity risk premium predictability is more than twice for recessions as compare to expansions.

Below given equation represents the Principal component predictive regression (PC-TECH model) Assuming $\mathrm{xt}=$ $(\mathrm{x} 1, \mathrm{t}, \ldots \ldots . . \mathrm{xN}, \mathrm{t})$ denote the $\mathrm{N}$-vector of all the 14 Technical indicators. We replaced $\hat{F}_{t}^{E C O N}$ with ${ }^{\wedge} \hat{F}_{t}^{T E C H}$ in equation (10). $\widehat{F}_{t}^{T E C H}=\widehat{F}_{1}^{T E C H} \ldots \ldots \hat{F}_{k}^{T E C H}$ symbolizes vector containing first $\mathrm{K}$ principal component extracted from $\mathrm{Xt}$ (where $\mathrm{K}<<\mathrm{N}$ ).

$$
r_{t+1}=\alpha+\sum_{k=1}^{K} \beta_{k} \hat{F}_{k, t}^{T E C H}+\varepsilon_{t+1}
$$

Regarding the amount of principal components used in the predictive setting, we employ the Schwarz information criterion (SIC), assuming a maximum number of three common components based on the set of 14 economic variables and technical indicators, and four based on the full set of 28 predictors.

Table 4.2 Predictive Regressions Based on Principal Components

\begin{tabular}{|c|c|c|c|c|c|c|}
\hline & $\begin{array}{l}\text { Slope } \\
\text { coefficient }\end{array}$ & t-statistic & $\begin{array}{l}\text { One-sided } \\
\text { (upper-tail) } \\
\text { wild } \\
\text { bootstrapped } \\
\text { p-value }\end{array}$ & R2 & $\begin{array}{l}\text { R2, } \\
\text { expansion }\end{array}$ & $\mathrm{R} 2$, recession \\
\hline \multicolumn{7}{|c|}{ MACRO-ECONOMIC VARIABLES } \\
\hline \multicolumn{7}{|c|}{ Principal components } \\
\hline F1-ECON & -0.0177 & $\begin{array}{l}-0.1799 \\
\end{array}$ & 0.5280 & 0.0000 & & \\
\hline \multicolumn{7}{|l|}{ F2-ECON } \\
\hline \multicolumn{7}{|l|}{ F3-ECON } \\
\hline \multicolumn{7}{|c|}{ TECHNICAL INDICATORS } \\
\hline \multicolumn{7}{|c|}{ Principal components } \\
\hline F1-TECH & -0.1556 & -1.5235 & 0.9390 & 0.0084 & & \\
\hline \multicolumn{7}{|l|}{ F2-TECH } \\
\hline \multicolumn{7}{|l|}{ F3-TECH } \\
\hline \multicolumn{7}{|c|}{ MACRO-ECONOMIC VARIABLES \& TECHNICAL INDICATORS } \\
\hline \multicolumn{7}{|c|}{ Principal components } \\
\hline F1-ALL & -0.1184 & -1.2458 & 0.8650 & $1.9122 \%$ & $0.2251 \%$ & $5.8366 \%$ \\
\hline F2-ALL & 0.0434 & 0.4650 & 0.3290 & & & \\
\hline F3-ALL & -0.0527 & -0.5107 & 0.6650 & & & \\
\hline F4-ALL & 0.2978 & 1.6390 & 0.0540 & & & \\
\hline F5-ALL & -0.1184 & $\begin{array}{l}-1.2458 \\
\end{array}$ & 0.8650 & & & \\
\hline F6-ALL & 0.0434 & 0.4650 & 0.3290 & & & \\
\hline
\end{tabular}

Table 4.2 represents the estimation results of equation (11) with $\mathrm{K}=1$. In case of technical indicators the coefficient estimates on the first principal component becomes significant at $5 \%$ level. Further the R2 of the model is $0.86 \%$. So, we can infer that the technical indicators taken as a group can significantly predict the equity risk premium. Further, the table also reports the return predictability of technical indicators for expansion and recession. The result shows R2 results of recession as $3.32 \%$.

The author also investigated the predictive power of all 28 variables i.e set of 14 macro-economic variables and 14 technical indicators by estimating predictive regression based on $\hat{F}_{t}^{A L L}$ (PC-ALL-Model).

1 The $\mathrm{K}$ value of four is selected by the adjusted $\mathrm{R} 2$. We consider a maximum $\mathrm{K}$ value of four since we now extract principal components from 28 potential predictors. The value of four is also the sum of the respective $\mathrm{K}$ values selected for the PC-ECON and PC-TECH models. 


$$
r_{t+1}=\alpha+\sum_{k=1}^{K} \beta_{k} \hat{F}_{k, t}^{A L L}+\varepsilon_{t+1}
$$

where $\hat{F}_{t}^{A L L}=\hat{F}_{1}^{A L L} \ldots \ldots \hat{F}_{k}^{A L L}$ denotes Vector containing first $\mathrm{K}$ principal components extracted from zt= $\left(\mathrm{x}^{\prime} \mathrm{t}, \ldots \ldots . . \mathrm{S}^{\prime} \mathrm{t}\right)$, the $2 \mathrm{~N}$ vector of 14 macro-economic variables and 14 technical indicators.

Panel $\mathrm{C}$ of Table 4.3 reveals that the coefficient estimates of $\hat{F}_{1, t}^{A L L}$ and $\hat{F}_{6, t}^{A L L}$ are significant in the PC-ALL model at the $1 \%$, and $5 \%$ levels, respectively. 1 However, coefficient estimates of $\hat{F}_{2, t}^{A L L}, \hat{F}_{3, t}^{A L L} \hat{F}_{4, t}^{A L L}$ and $\hat{F}_{5, t}^{A L L}$ were found to be insignificant. If we look at the R2 value of PC-All model we find the value to be $1.91 \%$ which is almost equal to the sum of R2 statistics of PC-ECON and PC-TECH models2. One can infer from this that both macro-economic variables and technical indicators contain complementary information. The table 4.3 also shows the $\mathrm{R} 2$ results of expansion and recession i.e. R2 EXP is . $23 \%$ and R2 REC is $5.84 \%$ statistics, thus we can say that the equity risk premium predictability in PC-All model is much stronger for recession as compared to expansions3.

\section{Behavior of Expected Equity Risk Premium around Cyclical Peaks and Troughs}

The following regressions provide further insight into the behavior of the expected equity risk premium around businesscycle peaks and troughs.

$$
\begin{aligned}
& r_{t}=\alpha_{A}+\sum_{m=4}^{-2} b_{A, m}^{p} l_{t-m}^{p}+\sum_{m=4}^{-2} b_{A, m}^{T} l_{t-m}^{T}+u_{A, t \prime} \\
& \hat{r}_{t}=\alpha_{F C}+\sum_{m=4}^{-2} b_{F C, m}^{p} l_{t-m}^{p}+\sum_{m=4}^{-2} b_{F C, m}^{T} l_{t-m}^{T}+u_{F C, t \prime}
\end{aligned}
$$

Where $\hat{r}$ is the equity risk premium forecast for all three models i.e. PC-ECON, PC-TECH and PC-ALL model. $I_{t}^{p}\left(I_{t}^{T}\right)$ is an indicator variable equal to one (unity) month $\mathrm{t}$ is NBER-dated business-cycle peak and zero when month $\mathrm{t}$ is NBERdated business-cycle trough. As per the given equation (13) $b_{A, m}^{p}\left(b_{A, m}^{T}\right)$ coefficient measures the average change in the actual ERP $m$ months from a cyclical peak and tough.

Similarly, $b_{F C, m}^{p}\left(b_{F C, m}^{T}\right)$ coefficient follows the same methodology given above. Equity market intuitively is a forward looking market therefore we used an asymmetric window including four months before and two months after a peak or trough. Results presented in tables above also show that equity risk premium predictability is more than twice for recessions as compare to expansions.

\subsection{Conclusion}

Equity premium prediction has been remained in focus of research. Welch and Goyal (2008) have revealed the high predictive capacity of standard economic variables till 1970s subsequently extinct. It is noticeable to check the predictive ability of technical indicators, after such viewpoint. Therefore, adding to the literature and to complement earlier work of (Baetje \& Menkhoff, 2015; Neely et al., 2014; Welch \& Goyal, 2008), this study compares the predictive competency of technical indicators and macro-economic variables. Complementing to this; possible instability is also considered to examine the forecasting ability.

Same set of 14 technical and 14 macro-economic variables are considered as by (Neely et al., 2014) to estimate predictive regression. Study endorses the economic indicators' instability by using different techniques and more data, as it was directed by (Welch \& Goyal, 2008). On the other hand, technical indicators are found less instable that signifies economic value of technical indicator-based forecasting.

1 We checked this result for various subsamples and found that the R2 for the PC-ALL model is not always equal to the sum of the R2 statistics for the PC-ECON and PC-TECH models, but they are always quite close.

2 We tested for structural breaks in all of the predictive regression models using the (Elliott \& Müller, 2006) qLL statistic, which is asymptotically efficient for a broad range of persistent breaking processes and has good size and power properties in the presence of heteroskedasticity. Overall, there is little evidence of structural instability in the predictive regressions.

${ }^{3} \mathrm{G}$. Marks, 'Structural Policy and Multi-level Governance in the EC, in A. Cafruny and G. Rosenthal (eds.), The State of the European Community, Volume 2: The Maastricht Debates and Beyond (Harlow: Longman, and Boulder, Co: Lynne Reiner, 1993). 
Regression results of Principal components that are taken out from PC-Tech and PC-Econ models (comprises of 14 technical indicators and 14 macro-economic variables respectively) disclose that these technical indicators and macroeconomic variables, both as a group predict equity risk premium significantly. It also shows that both these indicators hold different facts or information pertinent to equity risk premium prediction and therefore signify complementary perspectives to equity risk.

Expected equity risk premium estimations of PC-Econ and PC-Tech models, exhibit compatible counter cyclical patterns. As the downturn in actual equity risk premium nearly at the peaks of business cycle is better spotted by technical indicators, whereas the rise in actual equity risk premium nearly at the troughs of business cycle is well spotted by the macro-economic variables. Expected equity risk premium estimated by Principal component model of all indicators (PC-ALL model) shows more clearer countercyclical pattern. Expected equity risk premium estimated by PC-ALL model can better follow the sizable fluctuations in actual equity risk premium around peaks and troughs of business cycle through the highlighted countercyclical pattern.

In this study, technical indicators are used to forecast equity risk premium directly and to compare it with macro-economic variables and found that technical indicators have significant predictive power (statistically and economically) for the monthly ERP. Further, the study also aims to check the predictability of equity risk premium over the business cycle and found that the predictability is more than twice for recessions as compare to expansions.

Even, the role of technical indicators has been explained by various theories but yet not much is known about their capacity to explain the conventional facts about stock market returns, as equity risk premium puzzle (explained in introduction).

On the other hand, more traditional asset pricing models as the habit model of Campbell and Cochrane (1999) and longrun risks model of Bansal and Yaron (2004) can describe significant stylized facts but these models leave no role for technical analysis. It is important to link the gap between traditional assets pricing models and theoretical technical analysis models as the empirical evidence developing supports the technical indicator's predictive power. By exploring the association between these two types of models, our understanding of economic forces that drive equity risk premium and cross-section of the expected asset returns can be improved significantly.

\section{References}

[1] Ahn, D. H., Conrad, J., \& Dittmar, R. F. (2003). Risk adjustment and trading strategies. Review of Financial Studies, 16(2), 459-485.

[2] Annin, M., \& Falaschetti, D. (1998). Equity risk premium article. Ibbotson Associates.

[3] Arnott, R. D., \& Bernstein, P. L. (2002). What risk premium is "normal"? Financial Analysts Journal, 58(2), 6485.

[4] Baetje, F., \& Menkhoff, L. (2015). Equity premium prediction: Are economic and technical indicators instable? : Kiel Working Paper.

[5] Ball, R. (1978). Anomalies in relationships between securities' yields and yield-surrogates. Journal of Financial Economics, 6(2), 103-126.

[6] Bansal, R., \& Yaron, A. (2004). Risks for the long run: A potential resolution of asset pricing puzzles. The journal of finance, 59(4), 1481-1509.

[7] Bessembinder, H., \& Chan, K. (1995). The profitability of technical trading rules in the Asian stock markets. Pacific-Basin Finance Journal, 3(2), 257-284.

[8] Blume, L., Easley, D., \& O'hara, M. (1994). Market statistics and technical analysis: The role of volume. The Journal of Finance, 49(1), 153-181.

[9] Brock, W., Lakonishok, J., \& LeBaron, B. (1992). Simple technical trading rules and the stochastic properties of stock returns. Journal of finance, 1731-1764.

[10] Brown, S. J., \& Otsuki, T. (1993). Risk premia in Pacific-Basin capital markets. Pacific-Basin Finance Journal, 1(3), 235-261.

[11] Campbell, J. Y. (1987). Stock returns and the term structure. Journal of financial economics, 18(2), 373-399.

[12] Campbell, J. Y., \& Cochrane, J. H. (1999). Explaining the poor performance of consumption-based asset pricing models: National bureau of economic research.

[13] Campbell, J. Y., Lo, A. W.-C., \& MacKinlay, A. C. (1997). The econometrics of financial markets (Vol. 2): princeton University press Princeton, NJ. 
[14] Campbell, J. Y., \& Shiller, R. J. (1988). The dividend-price ratio and expectations of future dividends and discount factors. Review of financial studies, 1(3), 195-228.

[15] Campbell, J. Y., \& Thompson, S. B. (2008). Predicting excess stock returns out of sample: Can anything beat the historical average? Review of Financial studies, 21(4), 1509-1531.

[16] Campbell, J. Y., \& Vuolteenaho, T. (2004). Inflation illusion and stock prices: National Bureau of Economic Research.

[17] Chan, K. C., Karolyi, G. A., \& Stulz, R. (1992). Global financial markets and the risk premium on US equity. Journal of Financial Economics, 32(2), 137-167.

[18] Chordia, T., \& Swaminathan, B. (2000). Trading volume and cross-autocorrelations in stock returns. Journal of Finance, 913-935.

[19] Cochrane, J. H. (2011). Presidential address: Discount rates. The Journal of Finance, 66(4), 1047-1108.

[20] Conrad, J., \& Kaul, G. (1998). An anatomy of trading strategies. Review of Financial studies, 11(3), 489-519.

[21] Constantinidies, G. M., Donaldson, J. B., \& Mehra, R. (1998). Junior can't borrow: A new perspective on the equity premium puzzle: National Bureau of Economic Research.

[22] Damodaran, A. (2002). Investment valuation, 2. Aufl., New York, 817.

[23] Damodaran, A. (2011). Equity risk premiums (ERP): determinants, estimation and implications-the 2011 edition. Estimation and Implications

[24] Donaldson, R. G., Kamstra, M. J., \& Kramer, L. A. (2010). Estimating the equity premium.

[25] Edwards, R. (1957). Technical Analysis of Stock Trends (J. Magee, Springfield, Mass.). EdwardsTechnical Analysis of Stock Trends 1957.

[26] Elliott, G., \& Müller, U. K. (2006). Efficient tests for general persistent time variation in regression coefficients. The Review of Economic Studies, 73(4), 907-940.

[27] Elton, E. J., Gruber, M. J., Brown, S. J., \& Goetzmann, W. N. (2009). Modern portfolio theory and investment analysis: John Wiley \& Sons.

[28] Fama, E. F. (1976). Foundations of finance: Hwa-Tai.

[29] Fama, E. F., \& French, K. R. (1988a). Dividend yields and expected stock returns. Journal of financial economics, 22(1), 3-25.

[30] Fama, E. F., \& French, K. R. (1988b). Permanent and temporary components of stock prices. The Journal of Political Economy, 246-273.

[31] Fama, E. F., \& French, K. R. (1989). Business conditions and expected returns on stocks and bonds. Journal of financial economics, 25(1), 23-49.

[32] Fama, E. F., \& French, K. R. (1996). Multifactor explanations of asset pricing anomalies. The journal of finance, $51(1), 55-84$.

[33] Fama, E. F., \& French, K. R. (2002). The equity premium. The Journal of Finance, 57(2), 637-659.

[34] Fama, E. F., \& French, K. R. (2008). Dissecting anomalies. The Journal of Finance, 63(4), 1653-1678.

[35] Ferson, W. E., \& Harvey, C. R. (1999). Conditioning variables and the cross section of stock returns. The Journal of Finance, 54(4), 1325-1360.

[36] French, K. R., Schwert, G. W., \& Stambaugh, R. F. (1987). Expected stock returns and volatility. Journal of financial Economics, 19(1), 3-29.

[37] Gallant, A. R., Rossi, P. E., \& Tauchen, G. (1993). Nonlinear dynamic structures. Econometrica: Journal of the Econometric Society, 871-907.

[38] Gameiro, I. M. (2008). Equity Risk Premia Across Major International Markets. Economic Bulletin, 175-186.

[39] Goetzmann, W. N., \& Ibbotson, R. G. (2006). The equity risk premium: essays and explorations: Oxford University Press.

[40] Graham, J. R., \& Harvey, C. R. (2005). The long-run equity risk premium. Finance Research Letters, 2(4), 185194.

[41] Granville, J. E. (1963). New Key to Stock Market Profits: Prentice-Hall.

[42] Grundy, B. D., \& McNichols, M. (1989). Trade and the revelation of information through prices and direct disclosure. Review of financial Studies, 2(4), 495-526.

[43] Guvenen, F. (2009). A parsimonious macro-economic model for asset pricing. Econometrica, 77(6), 1711-1750.

[44] Hodrick, R. J. (1992). Dividend yields and expected stock returns: Alternative procedures for inference and measurement. Review of Financial studies, 5(3), 357-386. 
[45] Inoue, A., \& Kilian, L. (2005). In-sample or out-of-sample tests of predictability: Which one should we use? Econometric Reviews, 23(4), 371-402.

[46] Ito, A. (1999). Profits on technical trading rules and time-varying expected returns: evidence from Pacific-Basin equity markets. Pacific-Basin Finance Journal, 7(3), 283-330.

[47] Karpoff, J. M. (1987). The relation between price changes and trading volume: A survey. Journal of Financial and quantitative Analysis, 22(01), 109-126.

[48] Keim, D. B., \& Stambaugh, R. F. (1986). Predicting returns in the stock and bond markets. Journal of financial Economics, 17(2), 357-390.

[49] Kurz, M., Jin, H., \& Motolese, M. (2005). Determinants of stock market volatility and risk premia. Annals of Finance, 1(2), 109-147.

[50] Lettau, M., \& Ludvigson, S. (2001). Consumption, aggregate wealth, and expected stock returns. Journal of Finance, 815-849.

[51] Lettau, M., Ludvigson, S. C., \& Wachter, J. A. (2008). The declining equity premium: What role does macroeconomic risk play? Review of Financial Studies, 21(4), 1653-1687.

[52] Ludvigson, S. C., \& Ng, S. (2007). The empirical risk-return relation: a factor analysis approach. Journal of financial economics, 83(1), 171-222.

[53] Ludvigson, S. C., \& Ng, S. (2009). Macro factors in bond risk premia. Review of Financial Studies, hhp081.

[54] McCulloch, B. W., \& Leonova, D. (2005). The Market Equity Risk Premium. Available at SSRN 727583.

[55] Mehra, R., \& Prescott, E. C. (1985). The equity premium: A puzzle. Journal of monetary Economics, 15(2), 145161.

[56] Mele, A. (2007). Asymmetric stock market volatility and the cyclical behavior of expected returns. Journal of financial economics, 86(2), 446-478.

[57] Neely, C. J., Rapach, D. E., Tu, J., \& Zhou, G. (2014). Forecasting the equity risk premium: the role of technical indicators. Management Science, 60(7), 1772-1791.

[58] Neftci, S. N. (1991). Naive trading rules in financial markets and wiener-kolmogorov prediction theory: a study of" technical analysis". Journal of Business, 549-571.

[59] O'Hanlon, J., \& Steele, A. (2000). Estimating the equity risk premium using accounting fundamentals. Journal of Business Finance \& Accounting, 27(9-10), 1051-1083.

[60] Pratt y Grabowski, S. (2008). Cost of Capital: Applications and Example: New Jersey: John Wiley \& Sons.

[61] Rozeff, M. S. (1984). Dividend yields are equity risk premiums. Journal of Portfolio management, 68-75.

[62] Shiller, R. J., Fischer, S., \& Friedman, B. M. (1984). Stock prices and social dynamics. Brookings papers on economic activity, 457-510.

[63] Stambaugh, R. F. (1999). Predictive regressions. Journal of financial economics, 54(3), 375-421.

[64] Sullivan, R., Timmermann, A., \& White, H. (1999). Data-snooping, technical trading rule performance, and the bootstrap. Journal of Finance, 1647-1691.

[65] Welch, I., \& Goyal, A. (2008). A comprehensive look at the empirical performance of equity premium prediction. Review of Financial Studies, 21(4), 1455-1508.

[66] Zhu, Y., \& Zhou, G. (2009). Technical analysis: An asset allocation perspective on the use of moving averages. Journal of Financial Economics, 92(3), 519-544. 